\title{
Urea-formaldehyde microspheres as a potential additive to wood adhesive
}

\author{
Stefan Pinkl ${ }^{1}(1) \cdot$ Hendrikus W. G. van Herwijnen ${ }^{1} \cdot$ Stefan Veigel $^{2} \cdot$ Wolfgang Gindl-Altmutter $^{1,2} \cdot$ Martin Riegler $^{1}$
}

Received: 9 October 2017 / Accepted: 3 March 2018 / Published online: 9 April 2018

(c) The Author(s) 2018

\begin{abstract}
Urea formaldehyde (UF) resins are important for wood industry due to their attractive properties at reasonable price. Particulate fillers added to UF are of interest with regard to improving the functionality of UF and also in terms of reduced UF consumption. To study their potential as filler, solid UF microspheres were synthesized and characterised respecting its morphology, chemical curing and thermal stability. Marigold flower structured spheres with diameters between 5 and $20 \mu \mathrm{m}$ are presented and application trials demonstrated that high amounts of UF may be replaced by solid microspheres without impairing adhesive bond strength of solid wood bond lines. Fluorescence microscopy showed that microspheres greatly reduce adhesive penetration into the wood substrate, retaining the modified adhesive in the bondline. UF microspheres may thus be considered as viable filler for UF adhesives, particularly with regard to the possibility of endowing them with added functionality like self-healing properties.
\end{abstract}

Keywords Microparticles $\cdot$ Microscopy (optical, electron, fluorescence) $\cdot$ Resin substitution $\cdot$ Encapsulation

\section{Introduction}

Urea formaldehyde (UF) resins are widely used in wood industry because of their high reactivity, low cost and easy processing. Nearly all particleboards for indoor uses are bonded with UF resins despite ongoing concerns due to the critical discussion of formaldehyde emissions from this popular adhesive [1]. Hence, there is considerable pressure towards either replacing formaldehyde-based resins completely or substantially reducing formaldehyde emissions from adhesively bonded wood products. Modifications in the chemistry of UF, e.g., reductions in the molar ratio between urea and formaldehyde used in UF synthesis, have brought significant progress in emission reduction [2, 3]. An alternative strategy consists in the incorporation of non-UF additives either as formaldehyde scavenger or as UF-replacement.

Stefan Pinkl

s.pinkl@kplus-wood.at

1 Competence Centre for Wood Composites and Wood Chemistry, Wood K plus, 3430 Tulln, Austria

2 Department of Materials Science and Process Engineering, BOKU-University of Natural Resources and Life Sciences, 1180 Vienna, Austria
As an example, hydrolysed soy protein isolates were added to UF, which increased bonding strength, biodegradability and reduced formaldehyde emissions [4]. Corn flour improved mechanical performance and reduced formaldehyde emissions if added to UF [5]. A substitution up to $20 \%$ UF resin was reported using liquefied wood without impairing the mechanical properties of particleboards [6]. The co-condensation of UF with furfural proved to be feasible and resulted in reduced formaldehyde emissions at the expense of significantly increasing the necessary pressing temperatures [7].

Particulate additives may also reduce emissions from UF. Nanoclay was added to UF with the help of a coupling agent substituting up to $6 \%$ resin without negatively affecting its properties [8] or even improving its properties [9]. All these findings have shown that a substitute of a few percent of UF resin is possible without diminishing its properties. Silanised nanocellulose was also used successfully to reduce emissions while at the same time providing improved mechanical performance [10].

Besides formaldehyde emission, also the brittleness of cured UF resin presents a rewarding target for improvement [11]. Inorganic particles such as nanoclay [8, 9, 12-15] and cellulose nanoparticles [16-18] were successfully used as modifiers improving adhesive toughness and bond strength. 
Urea-modified scallop shell nanoparticles were added to plywood adhesives to reduce formaldehyde emissions [19].

In parallel to formaldehyde emission and adhesive mechanics, the addition of particulate fillers with high specific surface area, also significantly affected adhesive viscosity and, in turn, adhesive penetration into the bulk wood during application [18]. It is common sense in wood technology that adhesive penetration may be regarded as an indication of good wetting and that a certain penetration of adhesive into the wood bulk favours mechanical interlocking [20]. On the other hand, excessive penetration of adhesive is unwanted because this adhesive fraction does not directly contribute to the build-up of an adhesive bond line between neighbouring wood particles [18].

In summary, the addition of particulate fillers may be of interest towards improving bond performance and saving adhesive. Therefore, the present study focuses on expanding the available portfolio of potential particulate fillers for wood adhesives. Ideally, particulate filler should show good surface-chemical compatibility with UF, and a high specific surface area. These prerequisites are fulfilled by UF-microspheres [21], which are chemically identical with an UF wood adhesive and comprise of a high specific surface area. In the present study, UF-microspheres are synthesised and their suitability as an additive for improving UF adhesive bonds is elucidated.

\section{Experimental}

For the synthesis of UF microspheres according to the procedure described in reference [21], $0.1 \mathrm{~g}$ 2-hydroxyethyl cellulose (CAS Nr. 9004-62-0, Sigma-Aldrich Chemie GmbH, Germany) was dissolved in $100 \mathrm{ml}$ distilled water at $50{ }^{\circ} \mathrm{C}$ for $30 \mathrm{~min}$ under permanent stirring. Preliminary trials showed that hydroxyethyl cellulose with a molecular weight of $9 \times 10^{4} \mathrm{~g} / \mathrm{mol}$ yielded ideal spherical particles, whereas higher molecular weight of $1.3 \times 10^{6} \mathrm{~g} / \mathrm{mol}$ resulted in particles with heavily distorted geometry. Therefore, the lowmolecular weight variant was finally used. Subsequently, $8.11 \mathrm{~g}$ formaldehyde solution (37\%, CAS Nr. 50-00-0, Carl Roth GmbH \& Co. KG, Germany) was added, followed by the addition of $3 \mathrm{~g}$ crystalline urea (>99.5\%, CAS Nr. 57-136, Carl Roth GmbH \& Co. KG, Germany). The pH of the formulation was adjusted to $\mathrm{pH} 4$ with droplets of sodium hydroxide (0.1 mol/l, CAS Nr. 1310-73-2, Carl Roth GmbH \& Co. KG, Germany). After the addition of all chemicals, stirring was stopped and the temperature was kept at $50{ }^{\circ} \mathrm{C}$ for $3 \mathrm{~h}$. After a resting time of $24 \mathrm{~h}$, the microspheres had settled at the bottom of the flask. As a last step the supernatant was decanted, the spheres were washed with distilled water and dried by slow evaporation at room temperature and ambient pressure.
For microscopic studies of spheres, the microspheres were spread on carbon adhesive tape and observed with a scanning electron microscope (SEM, Quanta FEG 250, FEI, Czech Republic), operated with $5 \mathrm{kV}$ acceleration voltage. Before performing SEM studies, the microspheres were coated with gold using a sputter coater (Scancoat Six, HHV Ltd., United Kingdom) operated at $1 \mathrm{mbar}, 20 \mathrm{~mA}$ and $3-4 \mathrm{kV}$ for $240 \mathrm{~s}$.

The adhesive bond strength of microsphere-modified UF was evaluated using an industrial UF resin $(10 \mathrm{~F} 102$, Metadynea, Austria) to glue flawless beech veneers (Fagus sylvatica L.) for tensile shear testing inspired by EN 302-1 [22]. Strips of veneer $\left(150 \times 20 \times 0.5 \mathrm{~mm}^{3}\right)$ were glued with an overlapping area of $5 \times 20 \mathrm{~mm}^{2}$ and an adhesive spread of $200 \mathrm{~g} / \mathrm{m}^{2}$. UF microspheres were added to the adhesive at ratios of $0.0: 1,0.1: 1,0.5: 1$, and $1: 1$ with regard to the amount of solid UF present in the resin. Ammonium nitrate solution (60\%, CAS Nr. 6484-52-2, Carl Roth $\mathrm{GmbH} \& \mathrm{Co}$. KG, Germany) was used as hardener and its content was kept constant at $3 \%$ to the amount of solid resin in the system. For all formulations, the water content was adjusted in a manner that it was constant in relation to the sum of UF-microparticles, solid hardener and solid UF resin in the system. Prior to bonding, the adhesive formulations were exposed to an ultrasonic treatment for $3 \mathrm{~min}$ at $320 \mathrm{~W}$ and $35 \mathrm{kHz}$ (DT $100 \mathrm{H}$, Bandelin electronic, Germany).

Viscosity of each formulation was measured 3 times at a constant shear rate of $10 \mathrm{~s}^{-1}$ with a cone-plate rheometer (Bohlin Instruments CVO, Cranbury, USA) at $20^{\circ} \mathrm{C}$, for $240 \mathrm{~s}$, with 10 interpolation steps from which the penultimate values were used. To determine the pot life of adhesive formulations, the rheometer was adjusted to $40{ }^{\circ} \mathrm{C}$ and 3 measurements were executed immediately after adding the hardener and after 1 and $2 \mathrm{~h}$.

Both, specimen preparation (i.e., bonding of strips) and subsequent tensile testing were performed on a Zwick/Roell Z100 universal testing machine (Zwick GmbH \& Co. KG, Germany) equipped with a $5 \mathrm{kN}$ load cell and an electrically heated press. The glued strips were mounted to the testing machine and pressed together at 90 or $120^{\circ} \mathrm{C}$ for $2 \mathrm{~min}$ at a pressure of $25 \mathrm{kPa}$. Afterwards, the pressure was released and the sample was immediately tested to failure at a speed of $1.5 \mathrm{~mm} / \mathrm{min}$. For each adhesive formulation, a minimum of six specimens were tested, resulting in 85 specimens in total.

To characterise the cure dynamics of UF adhesive in the presence of UF microspheres, simultaneous thermal analysis (STA) was performed using a Netzsch STA 409 PG/1/G Luxx® (Netzsch Gerätebau GmbH, Germany). 4 mg of adhesive formulation (UF resin, hardener, UF microspheres and water) were put in $\mathrm{Al}_{2} \mathrm{O}_{3}$ crucibles, closed and pierced. Under nitrogen atmosphere (flow rate $50 \mathrm{ml} / \mathrm{min}$ ) 
the crucibles were heated from 25 to $300{ }^{\circ} \mathrm{C}$ at a heating rate of $10 \mathrm{~K} / \mathrm{min}$.

Wood specimens tested for adhesive bond strength were examined after failure using fluorescence microscopy to quantify penetration depth of the adhesive into the wood structure. Specimens measuring $5 \times 20 \mathrm{~mm}^{2}$ were cut from the middle of the veneers' overlapping area with a sharp paring chisel. They were immersed in a $0.1 \%$ Brilliant Sulphaflavine solution (CAS Nr. 2391-30-2, Sigma-Aldrich Chemie GmbH, Germany), a yellow fluorescent dye which bonds selectively to basic amino-groups [23], to stain the adhesive, for 2 min. After a washing step with $\mathrm{H}_{2} \mathrm{O}$, a second immersing step in a $0.1 \%$ Gentian Violet solution (CAS Nr. 548-62-9, Sigma-Aldrich Chemie GmbH, Germany) was added to stain the wood and create a good contrast between wood and adhesive [24]. Air-dried stained specimens were observed using a reflected-light microscope (Axioplan2, Carl Zeiss AG, Germany) with a $2.5 \times$ EC Epiplan-Neofluar objective mounted. A UV-lamp and the excitation filter Zeissset02 $(365 \mathrm{~nm})$ was used. Pictures were captured using a camera (Axiocam Hrc, Carl Zeiss AG, Germany) operated in RGB-mode. Digital image analysis was performed with ImageJ [25] creating one binary image of glue and one binary image of veneers bottom line.

The penetration depth was quantified in MATLAB (MathWorks Inc., USA), whereas both binary images (glue and bottom line) as well as the thickness measurements of veneers were imported. The resolution of the images $(4.147 \mu \mathrm{m} / \mathrm{pixel})$ was set as variable for the subsequent calculations. The bottom line was then smoothed to remove artefacts from the thresholding, using a moving average with a window length of 70 pixels. In preliminary tests, this window length was found to represent the given bottom lines most precisely. Afterwards the Euclidean distance was calculated from each single adhesive pixel to all pixels of the bottom line. The shortest Euclidean distance was selected and the veneer thickness was subtracted. This value was considered to be the penetration depth of single adhesive pixels in relation to the glued wood surface.

\section{Results and discussion}

The synthesis of UF-microspheres according to reference [21] was straightforward and resulted in UF powder as shown in Fig. 1. As expected, the particles were nicely spherical and disposed of a laminar substructure providing high specific surface area. The diameter of the spheres typically varied between 5 and $20 \mu \mathrm{m}$.

Different molecular weights of hydroxyethyl cellulose resulted in different shapes and surfaces of microspheres as shown in Fig. 2. At lower molecular weight, all spheres showed structured surfaces and were spherical beside a small amount with distorted geometry. With increasing molecular weight this proportion increased and especially the globular microspheres featured flat, unstructured surfaces. Dry powder as shown in Figs. 1 and 2 prepared with low molecular weight hydroxyethyl cellulose was used for all subsequent experiments without any further treatment.

Formulations of UF microspheres with an industrial adhesive prepared at different ratios exhibited different viscosities as shown in Table 1 . The reference's viscosity was around $300 \mathrm{mPa} \cdot \mathrm{s}$ and decreased with the addition of microspheres to $200 \mathrm{mPa} \cdot \mathrm{s}(-33 \%)$. However, the viscosity of the formulation containing 1 part microspheres and 1 part resin was higher and comparable with the reference's viscosity, measured immediately after adding the hardener. Remarkable was the high viscosity of the reference, 1 and
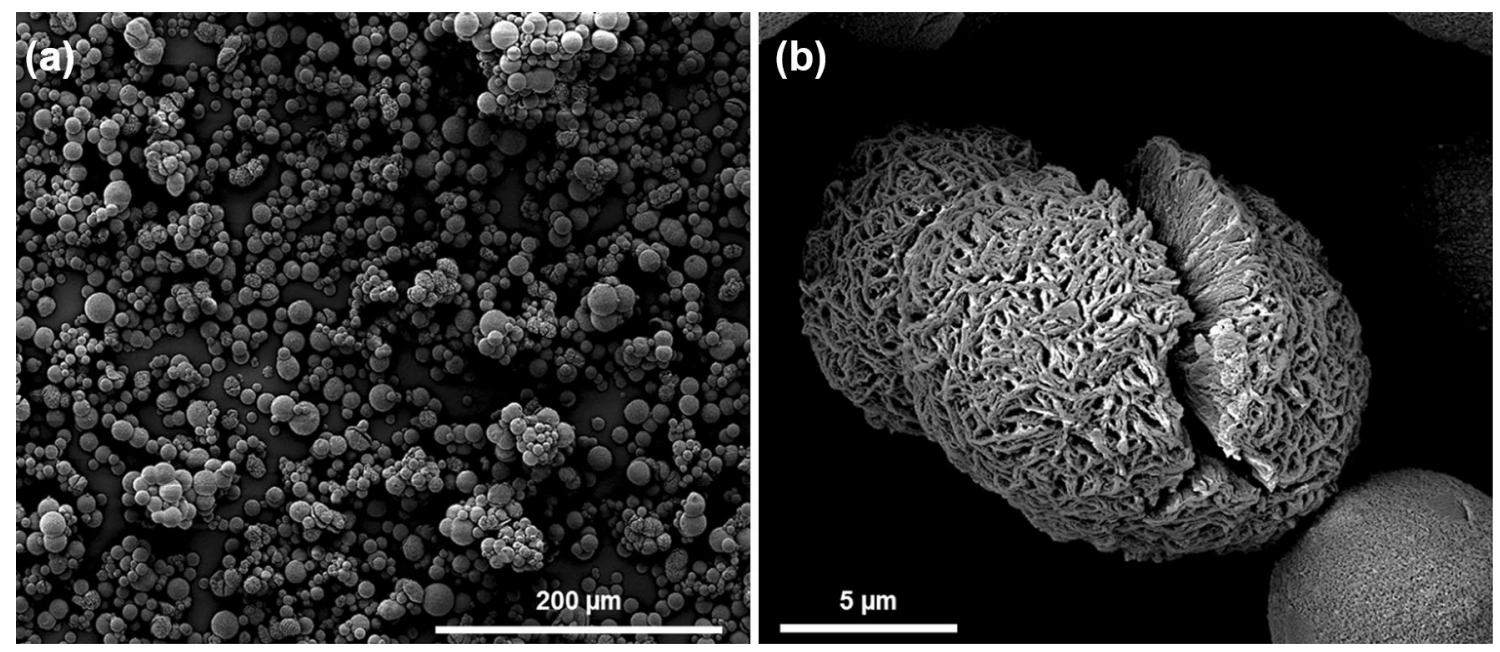

Fig. 1 Scanning electron microscopy picture of UF-microspheres at different magnifications; $\mathbf{a} \times 500, \mathbf{b} \times 1.2 \times 10^{4}$ 

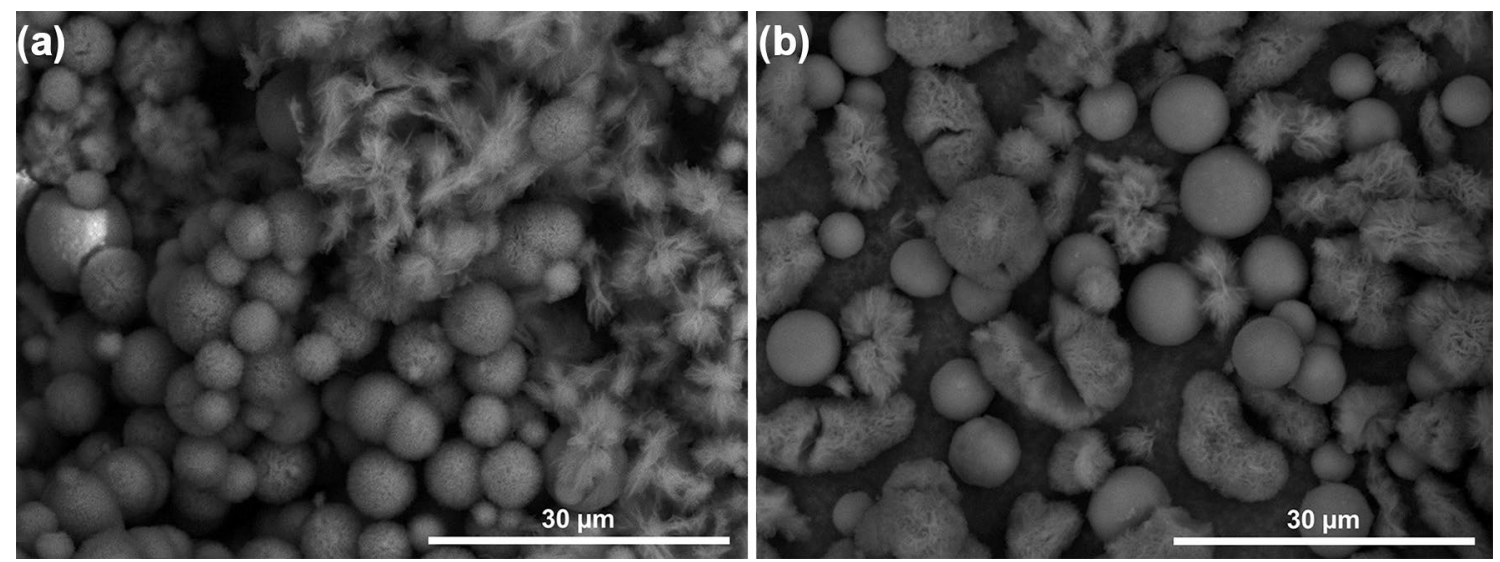

Fig. 2 Scanning electron microscopy picture of UF-microspheres at different molecular weights of hydroxyethyl cellulose; a $9 \times 10^{4} \mathrm{~g} / \mathrm{mol}, \mathbf{b}$ $1.3 \times 10^{6} \mathrm{~g} / \mathrm{mol}$

Table 1 Viscosities of different resin-microsphere formulations measured with a cone/plate rheometer at a constant shear rate of $10 \mathrm{~s}^{-1}$, at 20 and $40{ }^{\circ} \mathrm{C}$, immediately after hardener addition, as well as 1 and $2 \mathrm{~h}$ afterwards, to determine pot life

\begin{tabular}{lllll}
\hline $\begin{array}{l}\text { Ratio of } \\
\text { microspheres:resin }\end{array}$ & \multicolumn{4}{l}{ Viscosity $[\mathrm{mPa} \cdot \mathrm{s}]$} \\
\cline { 2 - 5 } & $0 \mathrm{~h}$ & & $1 \mathrm{~h}$ & $2 \mathrm{~h}$ \\
\cline { 2 - 5 } & $20^{\circ} \mathrm{C}$ & $40^{\circ} \mathrm{C}$ & & \\
\hline $0.0: 1$ & 312 & 348 & $1.02 \times 10^{3}$ & $6.81 \times 10^{4}$ \\
$0.1: 1$ & 245 & 284 & 665 & $2.91 \times 10^{4}$ \\
$0.5: 1$ & 191 & 232 & 331 & $1.34 \times 10^{3}$ \\
$1.0: 1$ & 298 & 375 & 397 & $1.07 \times 10^{3}$ \\
\hline
\end{tabular}

$2 \mathrm{~h}$ after the hardener addition. High viscosities were also measured for the formulation 0.1:1 (microspheres:UF). After $1 \mathrm{~h}$ the viscosities of the reference and the $0.1: 1$ formulation were $1 \times 10^{3}$ and $650 \mathrm{mPa} \cdot \mathrm{s}$, so still suitable for common industrial adhesive application systems. But after $2 \mathrm{~h}$ the viscosities increased to nearly $7 \times 10^{4}$ and $3 \times 10^{4} \mathrm{mPa} \cdot \mathrm{s}$, so they would not be applicable anymore. However, for the formulations $0.5: 1$ and $1: 1$, viscosities below $1 \times 10^{3} \mathrm{mPa} \cdot \mathrm{s}$ were measured. This observation can be explained by the lower content of hardener when microspheres were added, because hardener content was set constant to solid UF-resin content (3\%). By adding microspheres the content of reactive UF is successively replaced by microspheres, simultaneously reducing the hardener content. After $3 \mathrm{~h}$, all adhesive formulations were solid.

For the evaluation of bonding strength, the different adhesive formulations were applied to wood specimens. Unlike the reference, formulations containing microspheres appeared to be too dry and solidify very quickly after application, although pot life increases. This could be an indication that the liquid part of the formulation was soaked up by the wood bulk very quickly and only the solid microspheres

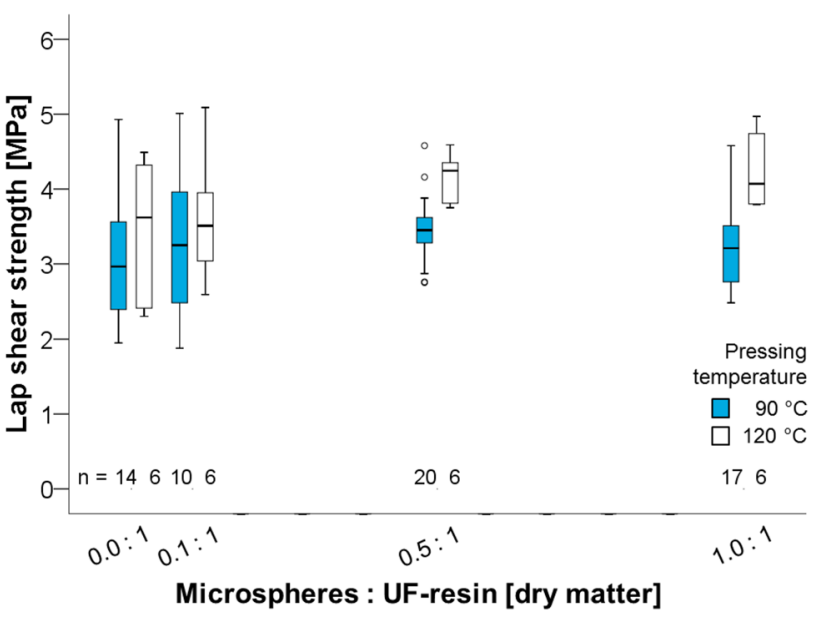

Fig. 3 Adhesive bond strength of wood specimens bonded with UF resin modified with different amounts of UF-microspheres cured at two different temperatures (t-bars: $1.5 \times$ height of box or, if no value in that range, minimum or maximum values)

were visible on the veneer's top. However, the overall processing and cure-behaviour was unaffected and comparable to the unmodified adhesive.

The adhesive bond strength of veneer specimens bonded with unmodified and microsphere-modified UF showed some effects of microsphere addition, which were, however, not significant in a statistical sense due to high variability within groups (Fig. 3). Overall, the bond strength of specimens cured at higher temperature was higher, as expected from UF cure-kinetics [2]. The lowest average values of bond strength were observed for the two variants bonded with unmodified adhesive, with $3.1 \mathrm{MPa}$ at $90{ }^{\circ} \mathrm{C}$ and $3.5 \mathrm{MPa}$ at $120^{\circ} \mathrm{C}$. Consistently, for both temperatures a slight but consistent increase in bond strength with increasing microsphere content was observed (Fig. 3). In fact, the highest values for adhesive strength were measured using 
an adhesive formulation containing 1 part resin (dry mass basis) and 1 part microspheres cured at $120{ }^{\circ} \mathrm{C}$. With an average value of $4.2 \mathrm{MPa}$, an increase of $20 \%$ was achieved. While these results do not demonstrate substantial improvements in bond strength, they provide clear proof that a high fraction of dry cured UF microsphere powder can be added to UF adhesive without impairing bond performance.

A comparison of the cure-kinetics of the two most extreme adhesive variants used, i.e., unmodified UF adhesive and adhesive containing equal amounts of resin and solid UF microspheres is shown in Fig. 4. While at lower temperatures the signal of differential scanning calorimetry (DSC) was primarily due to evaporating humidity, exothermal curing of the unmodified adhesive started at around $70{ }^{\circ} \mathrm{C}$ and reached a maximum at $90{ }^{\circ} \mathrm{C}$, which is in good agreement with literature [26-29].

In comparison to the unmodified adhesive, the formulation containing microspheres showed similar cure-behaviour, with the notable difference of a less intense maximum at $90^{\circ} \mathrm{C}$. This difference can be explained with the fact that the amount of reactive material was reduced by $50 \%$ in the modified adhesive. At $130{ }^{\circ} \mathrm{C}$ both formulations showed a sharp and intense endothermal peak related to endothermic formaldehyde elimination [26] creating ethylene bonds out of ether bonds, while releasing formaldehyde. Endothermal resin decomposition started at $215{ }^{\circ} \mathrm{C}$ for the unmodified adhesive and at $220^{\circ} \mathrm{C}$ for the modified one. In good agreement with literature [28], the strong endothermal peak corresponds to a distinct mass-drop in the signal of thermogravimetric analysis.

In summary, the addition of UF-microspheres to UF-resin did not affect its curing behaviour. Differences in peak intensity could be explained by reaction kinetics known from literature. The finding that adhesive strength remained unaffected or even improved slightly when $50 \%$ of reactive UF resin was replaced with largely inert UF-microspheres (ratio 1:1), remained to be explained. To do so, adhesive bond lines and, in particular, adhesive penetration, was examined. Excellent contrast between the adhesive and the bulk wood was obtained with the double-staining method applied seen in Fig. 5. Already upon optical inspection, clear differences between specimens bonded with unmodified adhesive and formulations modified with UF-microspheres were clearly visible. Unmodified UF penetrated deeper into the wood
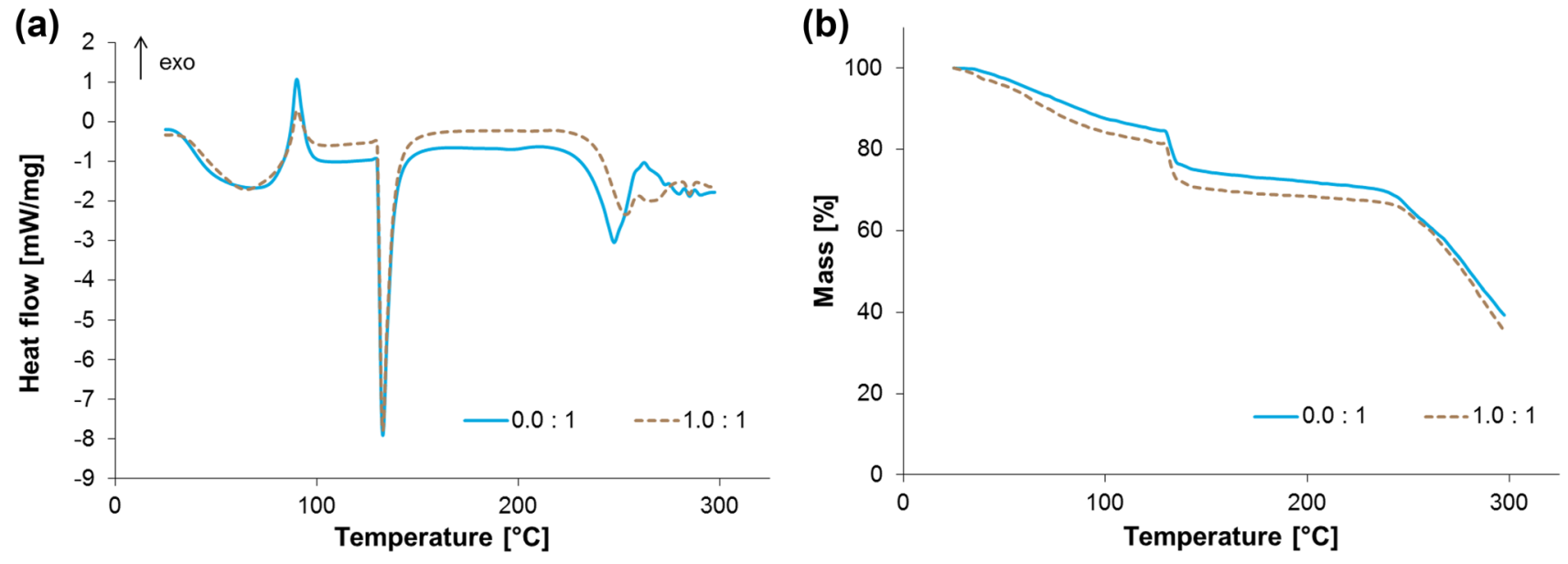

Fig. 4 Differential scanning calorimetry (a) and thermogravimetric analysis (b) of unmodified UF and adhesive containing equal amounts of resin and solid UF microspheres

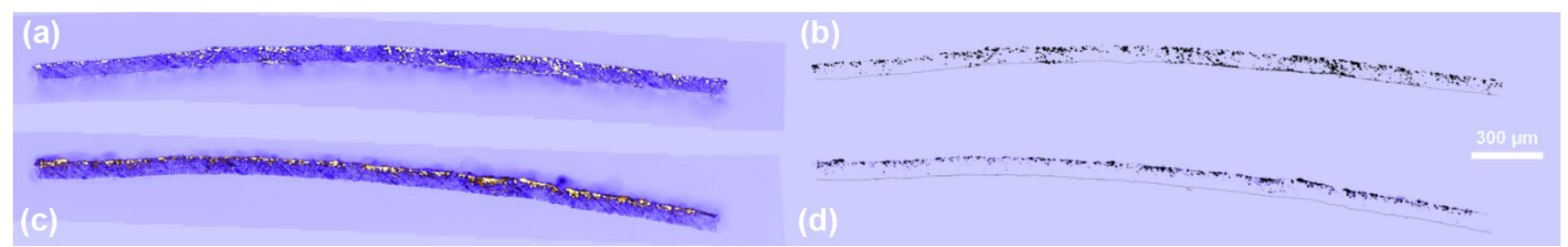

Fig. 5 Cross sections of wood specimens after adhesive bond strength testing stained with Brilliant Sulphaflavin and Gentian Violet. Reference specimen (0.0:1) in pseudo colour (a) and as binary picture (b) where glue and the veneer's bottom line are black. Same ratio microspheres and UF-resin (1.0:1) in pseudo colour (c) and as binary picture $(\mathbf{d})$ 


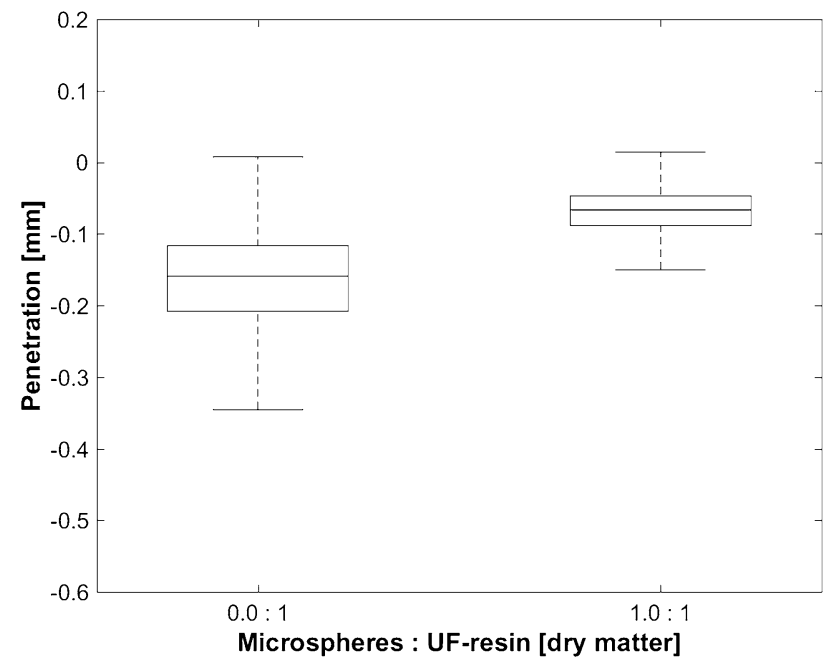

Fig. 6 Variability of adhesive penetration into the wood bulk for two adhesive formulations (t-bars: $1.5 \times$ height of box or, if no value in that range, minimum or maximum values)

(Fig. 5a, b) than the modified UF, which was concentrated close to the specimen surface (Fig. $5 \mathrm{c}, \mathrm{d}$ ). In quantitative terms, the average penetration was around $0.15 \mathrm{~mm}$ for unmodified UF and $0.08 \mathrm{~mm}$ for modified UF (Fig. 6).

Viscosity is a characterizing factor for the penetration behaviour of liquids. Rheological behaviour changed with the addition of microspheres. The observed initial decrease followed by a later increase in viscosity (Table 1) could be because of the microspheres' morphology. Balls enable an easy scrolling within the UF matrix, but at certain levels the loading is too high staunching the flow of UF and microspheres. This speculation is in good comparison with a study suggesting an explanation for comparable rheological behaviour in dispersions of silica nanospheres and montmorillonite platelets and their interaction [30].

Penetration was measured at unmodified adhesives and with maximum addition of microspheres, whereas both formulations exhibited comparable viscosities. Thus, the viscosity can be excluded to explain decreased penetration and the microsphere addition led to a decrease of resin's penetration depth to the half value measured at unmodified adhesive.

In addition to penetration depth, also the variability of penetration depth was significantly reduced at the modified variant, indicating a distinct concentration of adhesive close to the specimen surface. One explanation could be that the microspheres remain on the specimen surface, being solid bodies unable to penetrate the solid wood structure due to the above-micron size. It is proposed that due to the large specific surface area, substantial amounts of liquid adhesive adsorb to the surface of microspheres and consequently remain immobilised at the wood surface, reducing overall penetration. In good agreement with a recent study on UFadhesive modified with microfibrillated cellulose [18] it is proposed that the concentration of adhesive at the specimen surface, provided by UF-microsphere addition, enables the formation of bonds with strength similar to unmodified adhesive. There only a fraction of adhesive contributes to bond formation while a substantial amount of resin penetrates deeply into the bulk and does not contribute to bonding.

While interesting and unexpected effects were found in the present study, its practical significance remains unclear. It is intriguing that substantial amounts of inert additive can be added to an adhesive without impairing its bond strength. This finding may provide a basis for further studies, where UF microspheres provided with added functionality such as, e.g., free methylol groups immobilizing enzymes [31], or microencapsulated fragrances compensating unwanted terpene smells from wood [32], are incorporated into the bondline. Furthermore, aminoplastics are a major polymer used in microencapsulation [33, 34]. Microencapsulation is widely discussed in terms of providing additional functionality to coatings [35] or polymers in general [36]. Since the present study has shown that the addition of UF microspheres is feasible without degrading bond strength, it should also be feasible to incorporate aminoplastic microcapsules with, e.g., self-healing functionality into wood adhesive bond lines. Especially interesting for particleboard manufacturers using UF as adhesive with its high brittleness, self-healing is of high importance to enhance service life of furniture for example. Some studies already report a microencapsulation of polymerizable fluids as healing agent like dicyclopentadiene, styrene, or epoxy [37-39].

\section{Conclusions}

To conclude, a substitution of 50\% UF resin by solid microspheres (ratio 1:1) is possible, without impairing the bonding quality of solid wood joints. This opens the option of adding a huge amount of spherical particles directly into a bond line as carrier for, e.g., formaldehyde catchers or selfhealing substances. Lap shear strength indicates the quality of a wood joint and was tested at different substitution degrees and temperatures, where it did not underperform against the unmodified adhesive. The spheres did not influence the chemical curing of UF but if added, the penetration of liquid adhesive into wood was decreased by $50 \%$. The finding that adhesive stays closer to the bond line could be preferable if self-healing substances are added to repair damaged glue joints, but this is topic of further research.

Acknowledgements Open access funding provided by University of Natural Resources and Life Sciences Vienna (BOKU). The project was 
funded by the Austrian Research Promotion Agency (FFG) in collaboration with the Fritz Egger $\mathrm{GmbH} \& \mathrm{Co}$., OG as industrial partner. Special thanks to Roland Mitter for DSC-measurements and to Stephan Frömel-Frybort helping with digital image analysis.

Funding This study was funded by Austrian Research Promotion Agency (FFG, Grant number 844608).

Open Access This article is distributed under the terms of the Creative Commons Attribution 4.0 International License (http://creativeco mmons.org/licenses/by/4.0/), which permits unrestricted use, distribution, and reproduction in any medium, provided you give appropriate credit to the original author(s) and the source, provide a link to the Creative Commons license, and indicate if changes were made.

\section{References}

1. Yu CWF, Crump DR (1999) Testing for formaldehyde emission from wood-based products-a review. Indoor Built Environ 8:280-286

2. Dunky M (1998) Urea-formaldehyde (UF) adhesive resins for wood. Int J Adhes Adhes 18:95-107

3. Frackowiak I, Warcok F, Fuczek D, Andrzejak C (2011) The influence of UF molar ratio on selected particleboard properties. Drewno 54:39-49

4. Qu P, Huang HY, Wu GF, Sun EH, Chang ZZ (2015) The effect of hydrolyzed soy protein isolate on the structure and biodegradability of urea-formaldehyde adhesives. J Adhes Sci Technol 29:502-517

5. Moubarik A, Mansouri HR, Pizzi A, Allal A, Charrier F, Badia MA, Charrier B (2013) Evaluation of mechanical and physical properties of industrial particleboard bonded with a corn floururea formaldehyde adhesive. Compos Part B-Eng 44:48-51

6. Janiszewska D, Frackowiak I, Mytko K (2016) Exploitation of liquefied wood waste for binding recycled wood particleboards. Holzforschung 70:1135-1138

7. Zhang JZ, Chen H, Pizzi A, Li YH, Gao Q, Li JZ (2014) Characterization and application of urea-formaldehyde-furfural cocondensed resins as wood adhesives. Bioresources 9:6267-6276

8. Xian D, Semple KE, Haghdan S, Smith GD (2013) Properties and wood bonding capacity of nanoclay-modified urea and melamine formaldehyde resins. Wood Fiber Sci 45:383-395

9. Salari A, Tabarsa T, Khazaeian A, Saraeian A (2012) Effect of nanoclay on some applied properties of oriented strand board (OSB) made from underutilized low quality paulownia (Paulownia fortunei) wood. J Wood Sci 58:513-524

10. Zhang H, Zhang J, Song SP, Wu GF, Pu JW (2011) Modified nanocrystalline cellulose from two kinds of modifiers used for improving formaldehyde emission and bonding strength of ureaformaldehyde resin adhesive. Bioresources 6:4430-4438

11. Stoeckel F, Konnerth J, Gindl-Altmutter W (2013) Mechanical properties of adhesives for bonding wood-A review. Int J Adhes Adhes 45:32-41

12. Zahedsheijani R, Faezipour M, Tarmian A, Layeghi M, Yousefi H (2012) The effect of $\mathrm{Na}+$ montmorillonite (NaMMT) nanoclay on thermal properties of medium density fiberboard (MDF). Eur J Wood Wood Prod 70:565-571

13. Zhou X, Pizzi A, Du G (2012) The effect of nanoclay on melamine-urea-formaldehyde wood adhesives. J Adhes Sci Technol 26:1341-1348

14. Cai XL, Riedl B, Wan H, Zhang SY, Wang XM (2010) A study on the curing and viscoelastic characteristics of melamine-urea-formaldehyde resin in the presence of aluminium silicate nanoclays. Compos Part a-Appl Sci Manuf 41:604-611

15. Lei H, Du GB, Pizzi A, Celzard A (2008) Influence of nanoclay on urea-formaldehyde resins for wood adhesives and its model. J Appl Polym Sci 109:2442-2451

16. Veigel S, Müller U, Konnerth J, Gindl W (2010) Cellulose fibers and nanofibrils for adhesive reinforcement. In: International Conference on Nanotechnology for the Forest Products Industry, Espoo, Finland, 27-29 Sept 2010. Proceedings pp 1370-1375

17. Veigel S, Müller U, Keckes J, Obersriebnig M, Gindl-Altmutter W (2011) Cellulose nanofibrils as filler for adhesives: Effect on specific fracture energy of solid wood-adhesive bonds. Cellulose 18:1227-1237

18. Mahrdt E, Pinkl S, Schmidberger C, van Herwijnen HWG, Veigel S, Gindl-Altmutter W (2016) Effect of addition of microfibrillated cellulose to urea-formaldehyde on selected adhesive characteristics and distribution in particle board. Cellulose 23:571-580

19. Yamanaka S, Magara K, Hirabayashi Y, Fujimoto T, Kuga Y (2017) Reduction of formaldehyde emission from plywood using composite resin composed of resorcinol-formaldehyde and urea-modified scallop shell nanoparticles. Wood Sci Technol 51:297-308

20. Stehr M, Johansson I (2000) Weak boundary layers on wood surfaces. J Adhes Sci Technol 14:1211-1224

21. Wang Y, Tu MJ, Li XY, Zhang JY, Cheng J (2015) Facile synthesis of marigold-like microspheres from urea formaldehyde with controllable morphology. Mater Lett 145:27-29

22. EN 302-1 (2013) Adhesives for load-bearing timber structures-Test methods-Part 1: determination of bond strength in longitudinal tensile shear strength. European Committee for Standardization, Brussels

23. Leemann U, Ruch F (1972) Cytofluorometric determination of basic and total proteins with sulfaflavine. J Histochem Cytochem 20:659-671

24. Mahrdt E, Stoeckel F, van Herwijnen HWG, Mueller U, Kantner W, Moser J, Gindl-Altmutter W (2015) Light microscopic detection of UF adhesive in industrial particle board. Wood Sci Technol 49:517-526

25. Schneider CA, Rasband WS, Eliceiri KW (2012) NIH Image to ImageJ: 25 years of image analysis. Nat Methods 9:671-675

26. Szesztay M, LaszloHedvig Z, Nagy P, Tudos F (1996) DSC characterisation of urea/formaldehyde condensates 2. Experiences with high pressure DSC cell. Holz Roh Werkst 54:399-402

27. Popovic M, Miljkovic J, Simendic JB, Pavlicevic J, Ristic I (2011) Curing characteristics of low emission urea-formaldehyde adhesive in the presence of wood. Wood Res-Slovakia 56:589-599

28. Siimer K, Kaljuvee T, Christjanson P (2003) Thermal behaviour of urea-formaldehyde resins during curing. J Therm Anal Calorim 72:607-617

29. Park BD, Kang EC, Park JY (2006) Differential scanning calorimetry of urea-formaldehyde adhesive resins, synthesized under different pH conditions. J Appl Polym Sci 100:422-427

30. Bailey L, Lekkerkerker HNW, Maitland GC (2014) Rheology modification of montmorillonite dispersions by colloidal silica. Rheol Acta 53:373-384

31. Vinod VP, Shinde S, D'Britto V, Shukla PG, Rao M (2006) Preparation and characterization of urea-formaldehyde-pepsin bioconjugate: a new biocatalyst system. Biotechnol Prog 22:1585-1590

32. Schmidt DG, Norbury RJ, Buttery HJ (1995) Coated perfume particles. European Patent Office, Vienna EP0397246

33. Liu X, Lee JK, Kessler MR (2011) Microencapsulation of selfhealing agents with melamine-urea-formaldehyde by the Shirasu porous glass (SPG) emulsification technique. Macromol Res 19:1056-1061 
34. Then S, Neon GS, Abu Kasim NH (2011) Performance of melamine modified urea-formaldehyde microcapsules in a dental host material. J Appl Polym Sci 122:2557-2562

35. Wazarkar K, Patil D, Rane A, Balgude D, Kathalewar M, Sabnis A (2016) Microencapsulation: an emerging technique in the modern coating industry. Rsc Adv 6:106964-106979

36. Brown EN, White SR, Sottos NR (2004) Microcapsule induced toughening in a self-healing polymer composite. J Mater Sci 39:1703-1710
37. Wang H, Yuan Y, Rong M, Zhang M (2009) Microencapsulation of styrene with melamine-formaldehyde resin. Colloid Polym Sci 287:1089-1097

38. Yuan L, Liang GZ, Xie JQ, Li L, Guo J (2006) Preparation and characterization of poly(urea-formaldehyde) microcapsules filled with epoxy resins. Polym 47:5338-5349

39. Yuan L, Liang GZ, Xie JQ (2007) Synthesis and characterization of microencapsulated dicyclopentadiene with melamine-formaldehyde resins. Colloid Polym Sci 285:781-791 